\title{
Frequência das doenças de pele não tumorais em cães no município de João Pessoa, Paraíba, Brasil (2014-2016)
}

\author{
[Frequency of non Tumor Skin Diseases in Dogs in the City of João Pessoa, Paraíba \\ Brazil (2014-2016)] \\ J.S. Vasconcelos ${ }^{1}$, R.S. Siqueira ${ }^{2}$, I.J. Clementino ${ }^{3}$, A. Gama ${ }^{4}$, \\ A. Alves ${ }^{4}$, R.B. Lucena ${ }^{2}$, A.F.M. Dantas ${ }^{5}$ \\ ${ }^{1}$ Faculdades Nova Esperança - João Pessoa, PB \\ ${ }^{2}$ Aluno de pós-graduação - Hospital Veterinário -Patos, PB \\ ${ }_{3}^{3}$ Universidade Federal da Paraíba - Areia, PB \\ ${ }^{4}$ Universidade de Trás-os-Montes e Alto Douro - Vila Real - Portugal \\ ${ }^{5}$ Universidade Federal de Campina Grande - Patos, PB
}

\begin{abstract}
RESUMO
Diante da carência de estudos sobre a frequência de dermatopatias que acometem cães por região geográfica no Brasil, o presente estudo objetivou conhecer a frequência das principais doenças cutâneas que afetam cães na região metropolitana de João Pessoa, Paraíba, Brasil. Os dados foram coletados de cães que passaram por atendimento dermatológico no período de setembro de 2014 a dezembro de 2016. Além dos exames clínicos e dermatológicos os cães foram submetidos a exames complementares (citológico, raspado de pele, parasitológico, tricograma, bacteriológico, micológico, histopatológico e molecular). No período do estudo, foram atendidos 1.083 cães, em que 18,65\% (202/1.083) apresentavam algum tipo de dermatopatia não tumoral. Dos 202 cães acometidos, 51,49\% (104/202) eram machos e 48,51\% (98/202), fêmeas. Desses 202 cães, 13 tinham dois diagnósticos, totalizando 215 dermatopatias. Dos cães afetados, 62,87\% (127/202) eram de raça definida e $37,13 \%$ (75/202), sem raça definida (SRD). As lesões observadas com mais frequência caracterizaram-se por áreas alopécicas, hipotricoicas, maculosas, erosivas e ulcerativas, placoides, eritematosas, assim como comedões, colaretes, seborreia. As dermatopatias parasitárias foram as mais frequentes $(35,35 \% ; 76 / 215)$, seguidas pelas dermatopatias bacterianas $(24,19 \% ; 52 / 215)$, dermatopatias alérgicas $(20,00 \% ; 43 / 215)$, dermatopatias fúngicas $(17,21 \% ; 37 / 215)$, dermatopatias por outras causas $(2,32 \% ; 5 / 215)$ e pelas dermatopatias autoimunes $(0,93 \%$; $2 / 215$ ). Os exames físicos e dermatológicos, incluindo anamnese detalhada, histórico clínico apurado, associado a exames complementares, são ferramentas importantes para o diagnóstico das dermatopatias em cães. Presumese que a frequência de dermatopatias em cães na região de estudo possa ser maior do que a observada.
\end{abstract}

Palavras-chave: cães, dermatologia, exames complementares, doenças não tumorais

\begin{abstract}
Faced with the lack of studies on the frequency of dermatopathies that affect dogs by geographical region in Brazil, the present study aimed to evaluate the frequency of dermatopathies that affect the canine species in the metropolitan region of João Pessoa, Paraíba, Brazil. Data was collected from dogs that underwent dermatological care from September 2014 to December 2016. In addition to the clinical and dermatological examinations, dogs underwent complementary exams, such as cytological, skin scraping, parasitological skin examination, trichogram, bacteriological, mycological, histopathological and/or polymerase chain reaction. During the study period, 1,083 dogs were examined, in which 18.65\% (202 /1,083) had some form of non-tumoral dermatopathy. Of the 202 dogs affected, 51.49\% (104/202) were males and 48.51\% (98/202) females. Of these 202 dogs, thirteen had two diagnoses, totaling 215 dermatopathies. 62.87\% (127/202) of the affected dogs were purebred and $37.13 \%$ (75/202) were without a defined breed (WDB). The most frequently observed lesions were alopecia, hypotric, macular, erosive and ulcerative, placoid, erythematous areas, as well as comedones, collaretes and seborrhoea. The parasitic dermatopathies were the most frequent $(35.35 \% ; 76 / 215)$, followed by bacterial dermatopathies (24,19\%; 52/215), allergic dermatopathies (20,00\%; 43/215), dermatomycosis
\end{abstract}


(17,21\%; 37/215), dermatopathies for other causes $(2,32 \% ; 5 / 215)$ and autoimmune dermatopathies $(0.93 \%$; 2/215). Clinical and dermatological examination, including a detailed anamnesis, accurate clinical history and associated complementary exams are important tools for the diagnosis of dermatopathies in dogs. Available literature present some studies with canine dermatopathies frequencies superior to that obtained in the present study; however, the number of animals examined was smaller. In this survey, it was possible to establish the primary and secondary diagnoses in 100.0\% of the non-tumoral dermatopathies in dogs, results higher than in previous studies. Probably, the frequency of canine dermatopathies in this region is higher than that observed, thus requiring additional studies with greater sampling.

Keywords: dogs, dermatology, complementary exams, non-tumoral diseases

\section{INTRODUÇÃO}

O estudo das doenças de pele que afetam cães e gatos vem ganhando cada vez mais importância, tanto para os clínicos de pequenos animais quanto para os patologistas que têm interesse em dermatopatologia (Souza et al., 2009b). Embora a literatura internacional seja vasta, existem poucas informações disponíveis sobre a prevalência das dermatopatias de acordo com as diferentes regiões geográficas (Scott et al., 2013). Além disso, os poucos estudos epidemiológicos existentes são, na grande maioria, internacionais, não refletindo a situação regional brasileira (Sischo et al., 1989; Hill et al., 2006).

O diagnóstico das dermatopatias baseia-se no histórico clínico, no exame dermatológico, nos dados epidemiológicos e nos exames complementares (Lucas, 2007). Os exames complementares são ferramentas essenciais para se chegar ao diagnóstico definitivo ou descartar outros diagnósticos (Medleau e Hnilica 2009; Souza et al., 2009a; Hargis e Ginn, 2013). Entre os exames complementares utilizados no diagnóstico dermatológico em cães e gatos, estão os exames micológicos, bacteriológicos, parasitológicos de pele, citopatológicos, histopatológico, tricograma, dosagens hormonais, testes bioquímicos, hemograma, diagnóstico por imagem, imunohistoquímica e as técnicas moleculares (polymerase chain reaction (PCR) e o sequenciamento genético) (Conceição et al., 2004; Gross et al., 2005; Souza et al., 2009b; Pereira et al., 2011). Diante da carência de informações sobre dermatopatias que acometem cães e da existência de poucos estudos por região geográfica, foi elaborado o presente estudo, com o objetivo de conhecer as dermatopatias que afetam cães e sua frequência na região metropolitana de João Pessoa, Paraíba, Brasil.

\section{MATERIAL E MÉTODOS}

Foram coletados dados de 1.083 cães que passaram por atendimentos dermatológicos em quatro clínicas veterinárias localizadas nos bairros de Mangabeira, Valentina de Figueiredo e Bancários, os quais pertencem à zona sul do município de João Pessoa, Paraíba, Brasil, no período de setembro de 2014 a dezembro de 2016. Para o levantamento dos dados clínicos e dermatológicos, foi utilizada ficha dermatológica adaptada de Souza et al. (2009b) em anexo, e realizados exames físico e dermatológico completos. Todos os cães com lesões cutâneas foram submetidos a algum exame dermatológico, como citológicos, raspado de pele (hidróxido de potássio - $\mathrm{KOH}$ ), tricograma, bacteriológico, micológico, histopatológico, dieta de substituição ou dieta de eliminação e terapia, de acordo com Medleau e Hnilica (2009) e Salzo e Larsso (2009). Os aspectos clínicos, dermatológicos e morfológicos foram estabelecidos seguindo-se os critérios e os padrões já descritos (Gross et al., 2005; Hargis e Ginn, 2013).

Nos casos em que foi necessário realizar biópsias cutâneas excisionais, deu-se preferência aos sítios onde havia lesões primárias não tratadas, como máculas, pápulas, vesículas, pústulas e vergões. Nos casos em que o animal não apresentava mais lesões primárias, foram coletadas amostras das lesões secundárias, como escamas, crostas, úlceras, comedões e escaras (Hargis e Ginn, 2013). As biópsias de pele, foram obtidas após os cães terem sidos sedados com xilazina $2 \%$, na dose de $0,5 \mathrm{mg} / \mathrm{kg} / \mathrm{pv}$; cetamina a $10 \%$, na dose de $10 \mathrm{mg} / \mathrm{kg} / \mathrm{pv}$; e lidocaína a $2 \%$, na dose de $7 \mathrm{mg} / \mathrm{kg} / \mathrm{pv}$. Amostras coletadas para o exame histopatológico foram fixadas em solução de formalina tamponada a 10\%, processadas rotineiramente para histologia e coradas pela hematoxilina-eosina (HE). Em alguns casos, foram realizadas técnicas histoquímicas especiais 
e biomoleculares (reação em cadeia da polimerase - PCR) e sequenciamento genético). A análise histopatológica foi realizada em um microscópio óptico Olympus BX43, com câmera acoplada Olympus SC30. As doenças de pele diagnosticadas foram classificadas por grupos de acordo com a causa: dermatopatias, parasitárias, alérgicas, fúngicas, bacterianas, autoimunes, entre outras (Cardoso et al., 2011; Gasparetto et al., 2013). Devido ao elevado número de casos em cujas fichas clínicas não constava a idade precisa dos cães, foi realizada uma divisão da idade dos animais em grupos etários (até um ano, de dois a cinco anos, de seis a nove anos e acima de 10 anos de idade), baseados em Pena (2007) e modificados. A análise estatística realizada foi descritiva, discriminando as frequências observadas (valor absoluto e respectivas percentagens).

\section{RESULTADOS}

No período de setembro de 2014 a dezembro de 2016, foram atendidos 1.083 cães, em que $18,65 \%$ (202/1.083) apresentavam algum tipo de dermatopatia não tumoral. Dos 202 cães acometidos, 51,49\% (104/202) eram machos e 48,51\% (98/202), fêmeas. Desses, 93,56\% (189/202) apresentavam apenas uma doença de pele e $6,44 \%$ (13/202), duas doenças de pele, totalizando 215 diagnósticos. Dos 13 cães com duas doenças de pele, dois eram sem raça definida e 11, de padrão racial definido. A idade dos cães foi variável: $33,17 \%(67 / 202)$ tinham até um ano, $37,62 \%$ (76/202) entre dois e cinco anos, $29,79 \%$ (42/202) entre seis e nove anos, e 8,41\% (17/202) acima de 10 anos. Os dados referentes aos diagnósticos das doenças de pele de cães, de acordo com os diferentes grupos, sexo e faixa etária, estão descritos na Tab. 1.

Quanto às raças, 62,87\% (127/202) tinham raça definida; $37,13 \%(75 / 202)$ eram sem raça definida (SRD). Os cães de raça definida incluíam Poodle e Pitbull, com 18,11\% (23/127) cada; Labrador, $12,60 \%$ (16/127); Rottweiller e Pinscher, 6,30\% (8/127) cada; Shi Tzu, 5,51\% (7/127); Pastor Alemão, 4,72\% (6/127); Dachshund e Maltês, 3,15\% (4/127) cada; Dálmata, 2,36\% (3/127); Bull Terrier, Pastor de Malinois, Pug, Boxer e Cocker Spainel,1,57\% (2/127) cada; América Starfordshire Terrier, Mastim Napolitano, Akita,
Buldog Francês, Lhasa Apso, Golden Retrievier, Buldog Inglês, Terrier Brasileiro e Schnauzer, correspondendo a $0,79 \%(1 / 127)$ cada. Em todos os casos, foram frequentes as lesões crônicas, caracterizadas por áreas alopécicas, hipotricoicas, maculosas, erosivas e ulcerativas, placoides, eritematosas, assim como comedões, colaretes, seborreia e, em alguns casos, a presença de ectoparasitas.

As dermatopatias parasitárias foram as mais frequentes, com 35,35\% (76/215) dos casos; o diagnóstico foi realizado com base no histórico clínico e no exame dermatológico, auxiliado por exame de raspado cutâneo clarificado com $\mathrm{KOH}$. Dentro desse grupo de dermatopatias, destacou-se a demodiciose (Demodex canis) (Fig. 1a e b), com $55,26 \%$ (42/76) dos casos, sendo 61,90\% (26/42) machos e $30,10 \%$ (16/42) fêmeas, a qual afetou animais de quatro meses a 14 anos de idade, com maior frequência no grupo com idade de até um ano, com 57,14\% (24/42) dos casos (Tab. 1). Os animais sem raça definida foram os mais acometidos (12/42; 28,57\%), Pitbull (6/42; $14,30 \%)$, Poodle (4/42; 9,52\%), Pinscher, Pastor Alemão, Bull Terrier e Maltês (3/42; 7,14\%) casos cada.

A escabiose (Sarcoptes scabiei) (Fig. 1c, d) foi a segunda dermatopatia parasitária mais diagnosticada, com 23,68\% (18/76) casos; destes, $50 \%$ (9/18) eram machos e 50\% (9/18), fêmeas. A idade variou de dois meses a três anos, sendo mais frequente no grupo com idade de até um ano, com $83,33 \%$ (15/18) dos casos, seguida dos animais de dois a cinco anos, com 16,67\% (3/18) dos casos (Tab. 1). As raças acometidas foram SRD, com 77,80\% (14/18); Poodle, 11,10\% (2/18); Pastor Alemão e Pitbull, cada uma com 5,55\% (1/18). As demais dermatoses parasitárias diagnosticadas foram: miíase $(15,79 \%$; 12/76), leishmaniose (Fig. 2 c, d) $(3,95 \%$; 3/76) e tunguíase $(1,31 \%$; 1/76). Em relação às raças, destaca-se a seguinte distribuição: miíase acometeu 50\% (6/12) de animais SRD, 25\% (3/12) Pitbull e, em menor frequência, Cocker Spaniel $(16,67 \% ; 2 / 12)$ e Pastor Alemão $(8,33 \% ; 1 / 12)$; a leishmaniose foi diagnosticada em três raças distintas (SRD, Boxer e Labrador), cada uma com um caso (33,33\%; 1/3); e a tunguíase diagnosticada em apenas um cão da raça Pitbull. 
Frequência das doenças...

Tabela 1. Distribuição das doenças cutâneas não tumorais diagnosticadas em cães, de acordo com os diferentes grupos, bem como sexo e faixa etária, no município de João Pessoa, Paraíba, Brasil, 2014 - 2016

\begin{tabular}{|c|c|c|c|c|c|c|c|c|c|c|c|c|c|c|}
\hline \multirow{3}{*}{ Diagnóstico } & \multirow{2}{*}{\multicolumn{2}{|c|}{ Total }} & \multicolumn{4}{|c|}{${ }^{\mathrm{a}} \mathrm{Sexo}$} & \multicolumn{8}{|c|}{ Faixa Etária } \\
\hline & & & \multicolumn{2}{|c|}{ Macho } & \multicolumn{2}{|c|}{ Fêmea } & \multicolumn{2}{|c|}{ Até 1 ano } & \multicolumn{2}{|c|}{2 a 5 anos } & \multicolumn{2}{|c|}{6 a 9 anos } & \multicolumn{2}{|c|}{$\geq$ a 10 anos } \\
\hline & $\mathrm{n}^{\mathrm{o}}$ & $\%$ & $\mathrm{n}^{\mathrm{o}}$ & $\%$ & $\mathrm{n}^{\mathrm{o}}$ & $\%$ & $\mathrm{n}^{\circ}$ & $\%$ & $\mathrm{n}^{\circ}$ & $\%$ & $\mathrm{n}^{\circ}$ & $\%$ & $\mathrm{n}^{\circ}$ & $\%$ \\
\hline $\begin{array}{l}\text { Dermatopatias } \\
\text { parasitárias }\end{array}$ & 76 & 35,35 & 48 & 63,16 & 28 & 36,84 & 43 & 56,58 & 18 & 23,68 & 10 & 13,16 & 5 & 6,58 \\
\hline Demodiciose & 42 & 55,26 & 26 & 61,90 & 16 & 30,10 & 24 & 57,14 & 10 & 23,81 & 5 & 11,91 & 3 & 7,14 \\
\hline Escabiose & 18 & 23,68 & 9 & 50,00 & 9 & 50,00 & 15 & 83,33 & 3 & 16,67 & 0 & 0 & 0 & 0 \\
\hline Mí́ase & 12 & 15,79 & 9 & 75,00 & 3 & 25,00 & 3 & 25,00 & 3 & 25,00 & 4 & 33,33 & 2 & 16,67 \\
\hline Leishmaniose & 3 & 3,95 & 3 & 100,0 & 0 & 0 & 0 & 0 & 2 & 66,67 & 1 & 33,33 & 0 & 0 \\
\hline Tunguíase & 1 & 1,32 & 1 & 100,0 & 0 & 0 & 1 & 100,0 & 0 & 0 & 0 & 0 & 0 & 0 \\
\hline $\begin{array}{l}\text { Dermatopatias } \\
\text { bacterianas }\end{array}$ & 52 & 24,19 & 25 & 48,08 & 27 & 51,92 & 11 & 21,15 & 25 & 48,08 & 12 & 23,08 & 4 & 7,69 \\
\hline Piodermite & 33 & 63,45 & 15 & 45,45 & 18 & 54,55 & 6 & 18,18 & 13 & 39,40 & 10 & 30,30 & 4 & 12,12 \\
\hline Paniculite b. Idiopática & 5 & 9,62 & 3 & 60,00 & 2 & 40,00 & 0 & 0 & 4 & 80,00 & 1 & 20,00 & 0 & 0 \\
\hline Abscesso subcutâneo & 5 & 9,62 & 3 & 60,00 & 2 & 40,00 & 1 & 20,00 & 4 & 80,00 & 0 & 0 & 0 & 0 \\
\hline Dermatites bacterianas & 5 & 9,62 & 1 & 20,00 & 4 & 80,00 & 2 & 40,00 & 3 & 60,00 & 0 & 0 & 0 & 0 \\
\hline Foliculite / funrunculose & 4 & 7,69 & 3 & 75,00 & 1 & 25,00 & 2 & 50,00 & 1 & 25,00 & 1 & 25,00 & 0 & 0 \\
\hline Dermatopatias alérgicas & 43 & 20,00 & 22 & 51,16 & 21 & 48,84 & 8 & 18,60 & 19 & 44,19 & 10 & 23,26 & 6 & 13,95 \\
\hline Dermatite atópica & 20 & 46,51 & 10 & 50,00 & 10 & 50,00 & 5 & 25,00 & 11 & 55,00 & 3 & 15,00 & 1 & 5,00 \\
\hline DAPE $^{*}$ & 12 & 27,91 & 8 & 66,67 & 4 & 33,33 & 2 & 16,67 & 4 & 33,33 & 4 & 33,33 & 2 & 16,67 \\
\hline Dermatite a H. Alimentar & 6 & 13,95 & 2 & 33,33 & 4 & 66,67 & 0 & 0 & 3 & 50,00 & 1 & 16,67 & 2 & 33,33 \\
\hline Dermatite de Contato & 4 & 9,31 & 2 & 50,00 & 2 & 50,00 & 1 & 25,00 & 0 & 0 & 2 & 50,00 & 1 & 25,00 \\
\hline Farmacodermia & 1 & 2,32 & 0 & 0 & 1 & 100,0 & 0 & 0 & 1 & 100,0 & 0 & 0 & 0 & 0 \\
\hline Dermatopatias Fúngicas & 37 & 17,21 & 15 & 40,54 & 22 & 59,46 & 9 & 24,32 & 18 & 48,67 & 7 & 18,91 & 3 & 8,10 \\
\hline Malasseziose & 28 & 75,67 & 13 & 46,43 & 15 & 53,57 & 8 & 28,58 & 11 & 39,28 & 6 & 21,43 & 3 & 10,71 \\
\hline Dermatofitose & 8 & 21,63 & 2 & 25,00 & 6 & 75,00 & 1 & 12,50 & 6 & 75,00 & 1 & 12,50 & 0 & 0 \\
\hline Esporotricose & 1 & 2,70 & 0 & 0 & 1 & 100,0 & 0 & 0 & 1 & 100,0 & 0 & 0 & 0 & 0 \\
\hline Outras dermatopatias & 05 & 2,32 & $\mathbf{0}$ & $\mathbf{0}$ & 5 & 100,0 & 1 & 20,00 & $\mathbf{0}$ & $\mathbf{0}$ & 2 & 40,00 & 2 & 40,00 \\
\hline Cistomatose apócrina & 02 & 40,00 & 0 & 0 & 2 & 100,0 & 0 & 0 & 0 & 0 & 1 & 50,00 & 1 & 50,00 \\
\hline Adenite Sebácea & 01 & 20,00 & 0 & 0 & 1 & 100,0 & 1 & 100,0 & 0 & 0 & 0 & 0 & 0 & 0 \\
\hline Cisto Interdigital & 01 & 20,00 & 0 & 0 & 1 & 100,0 & 0 & 0 & 0 & 0 & 1 & 100,0 & 0 & 0 \\
\hline Acantose nigricans & 01 & 20,00 & 0 & 0 & 1 & 100,0 & 0 & 0 & 0 & 0 & 0 & 0 & 1 & 100,0 \\
\hline $\begin{array}{l}\text { Dermatopatias } \\
\text { autoimunes }\end{array}$ & 02 & 0,93 & 1 & 50,00 & 1 & 50,00 & $\mathbf{1}$ & 50,00 & $\mathbf{0}$ & $\mathbf{0}$ & 1 & 50,00 & $\mathbf{0}$ & 0 \\
\hline Lúpus eritematoso & 02 & 100,0 & 1 & 50,00 & 1 & 50,00 & 1 & 50,00 & 0 & 0 & 1 & 50,00 & 0 & 0 \\
\hline Total: & & 15 & & $11 \%$ & & $7 \%$ & & $96 \%$ & & $\begin{array}{l}30 \\
21 \%)\end{array}$ & & $3 \%)$ & & $20 \%$ \\
\hline
\end{tabular}

"Dermatite alérgica a picada de ectoparasitas, ${ }^{\text {a }}$ Quantidade e percentual está relacionado ao número de diagnósticos.

As dermatopatias bacterianas apareceram em segundo lugar, com 24,19\% (52/215), diagnosticadas por meio de exame clínico, dermatológico, citológico e histopatológico. Dentre as dermatopatias desse grupo, destacam-se a piodermite, com $63,45 \%$ (33/52) casos, sendo $45,45 \%$ (15/33) em machos e 54,55\% (18/33) em fêmeas, acometendo animais de três meses a 13 anos, com mais frequência no grupo das idades de dois a cinco anos $(39,40 \% ; 13 / 33)$ (Tab. 1). Quanto ao padrão racial, 30,30\% (10/33) eram SRD; $21,74 \%$ (5/23) Labrador; 17,40\% (4/23) Pitbull; 13,04\% (3/23) Poodle e Rottweiller; $8,70 \%$ (2/23) Pastor Alemão e Shi Tzu; e 4,35\% (1/23) corresponderam a um animal de cada uma das raças: Lhasa Apso, Doberman e Dálmata.
A paniculite bacteriana idiopática, junto como abcesso cutâneo e a dermatite bacteriana apareceram em segundo lugar entre as dermatopatias bacterianas, com 9,62\% (5/52) cada, de acordo com a Tab. 1. Os cães diagnosticados com paniculite idiopática bacteriana eram SRD (60\%; 3/5), Dachshund $(20 \% ; 1 / 5)$ e Pastor de Malanois $(20 \% ; 1 / 5)$; os cães com abscesso subcutâneo eram SRD (40\%; 2/5) e um de cada uma das raças: Pitbull, Labrador e Pinscher $(20 \%$; $1 / 5)$; os animais acometidos de dermatite bacteriana eram das raças Pitbull (40\%; 2/5) e Mastim Napolitano, SRD e Poodle (20\%; 1/5), com um animal de cada uma dessas raças. As foliculite/furunculose foram diagnosticadas em $7,69 \%$ (4/52) dos cães, tendo acometido animais SRD, com 50\% (2/4); Pitbull e Poodle, com 25\% (1/4) cada. 


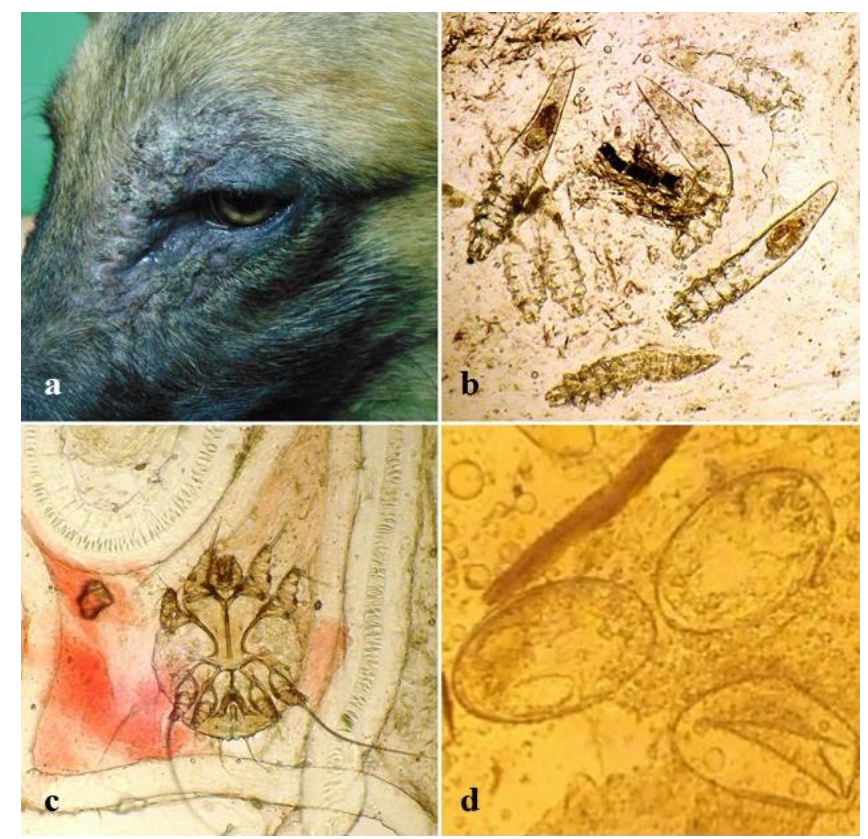

Figura 1. (a) Cão, macho, Pastor Alemão, quatro meses de idade, apresentando área alopécica associada a erosões na região periocular, com diagnóstico de demodiciose. (b) Exame parasitológico da pele do cão da Fig. 1a. Exemplares de D. canis obtidos a partir das lesões. 100x, KHO 20\%. (c) Exame parasitológico da pele de cão, fêmea, SRD, quatro meses de idade. Exemplar de S. scabiei. adulto. 100x, KHO 20\%. (d) Exame parasitológico da pele de cão, fêmea, SRD, quatro meses de idade. Ovos de S. scabiei. 100x, KHO $20 \%$.

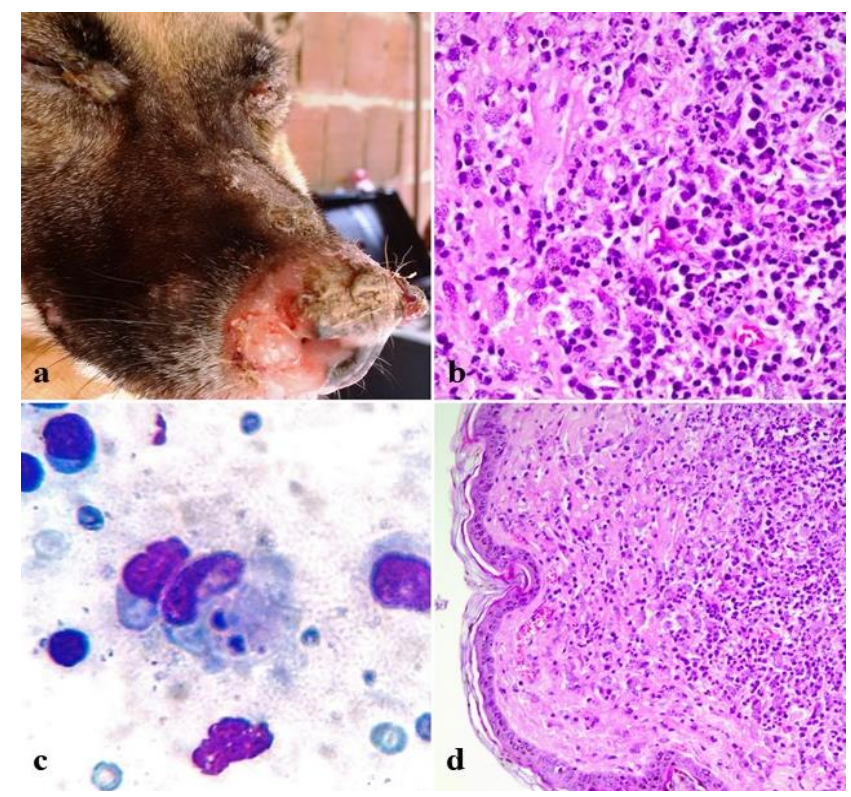

Figura 2. (a) Cão, macho, SRD, três anos de idade, diagnosticado com leishmaniose. Apresenta ulceração e descamação do assoalho nasal. Presença de secreção mucopurulenta nasal e ocular. (b e d) Cão, macho, Boxer, seis anos de idade. Dermatite plasmocitária, neutrofílica e granulomatosa, associada à presença de numerosas formas amastigotas de Leishmania sp. intracitoplasmáticas. 40x e 10x, HE. (c) Cão, macho, Labrador, dois anos de idade. Citologia do exsudado de lesão cutânea ulcerada. Macrófago contendo duas formas amastigotas de Leishmania sp. Citologia por imprint na lesão nasal do animal da Figu. 2a. 100x, panótico rápido. 
As dermatites alérgicas foram o terceiro grupo mais frequente, com $20 \% \quad(43 / 215)$ dos diagnósticos, acometendo 46,51\% (20/43) machos e 53,49\% (23/43) fêmeas. A idade variou de sete meses a 15 anos, sendo mais frequente no grupo de idade de dois a cinco anos (44,17\%; 19/43) (Tab. 1). Entre as dermatites alérgicas, a dermatite atópica foi a mais frequente, com $46,51 \%$ (20/43), tendo acometido 50\% (10/20) machos e $50 \%$ (10/20) fêmeas, sendo o grupo de idade mais afetado o de dois a cinco anos, com $55 \%(11 / 20)$ dos casos. Trinta por cento (6/20) dos cães afetados por dermatite atópica eram SRD e 70\% (14/20) tinham raça definida. Os cães com raças definidas eram Pinscher, Labrador e Pitbull, com 14,29\% (2/14) dos casos. As raças Poodle, Golden, Dachshund, Fox Paulistinha, Buldog Francês, Pug, Pastor Alemão e Cocker Spainel corresponderam a $7,14 \%(1 / 14)$, com um animal de cada raça.

A dermatite alérgica a picada de ectoparasitas (DAPE) foi a segunda dermatopatia alérgica mais diagnosticada, de acordo com a Tab. 1. Os cães afetados foram SRD, Pitbull, com 33,33\% (2/6); Poodle, Boxer, Pastor Alemão e Rottweiller, com $16,67 \%$ (1/6) cada. As outras dermatites alérgicas foram: hipersensibilidade alimentar, diagnosticada em 13,95\% (6/43) dos casos, dermatite de contato, diagnosticada em $9,31 \%$ (4/43), e a farmacodermia com 2,32\% (1/43). Quanto à distribuição racial, destaca-se, na hipersensibilidade alimentar, SRD, com $66,66 \%$ (4/6); Akita, com 16,67\% (1/6); e o Labrador, com $16,67 \%$ (1/6). Na dermatite de contato, 75\% (3/4) eram SRD e $25 \%(1 / 4)$ da raça Akita; o caso de farmacodermia foi diagnosticado em um Buldog Francês.

As dermatomicoses representaram 17,21\% (37/215) das dermatopatias diagnosticadas. A malasseziose (Malassezia pachydermatis), diagnosticada por exame citológico (Fig. 3a), foi a mais frequente, com $75,67 \%$ (28/37) dos casos. Dos cães acometidos, 53,57\% (15/28) eram fêmeas e 46,43\% (13/28), machos, com idade entre três meses a 15 anos, sendo mais afetado o grupo de dois a cinco anos, com 39,28\% (11/28) dos casos (Tab. 1). Os cães SRD representaram $32,15 \%$ (9/28) dos casos, seguindo-se os da raça Poodle, correspondendo a 31,58\% (6/19) dos casos.

A dermatofitose (Microsporum canis, Microsporum gypseum, Microsporum spp. e Trichophyton verrucosum), diagnosticada por meio de exame de raspado cutâneo e cultura microbiológica, ocorreu em 21,63\% (8/37) dos casos (Fig. 3 b, c), sendo 75\% (6/8) fêmeas e $25 \%$ $(2 / 8)$ machos, com idade variando de sete meses a três anos, sendo mais frequente $(75,0 \%, 6 / 8) \mathrm{em}$ animais de dois a cinco anos (Tab. 1). Dos cães acometidos, 25\% (2/8) eram SRD; 25\% (2/8) Poodle; $25 \%$ (2/8) Shi Tzu; e 12,50\% (1/6) corresponderam a Pinscher e Maltês, com um cão de cada raça. A esporotricose (Sporothrix brasiliensis) foi diagnosticada utilizando-se exame citológico, histopatológico, PCR e o sequenciamento genético para identificação do agente (Fig. 3d), com 2,70\% (1/33) das dermatomicoses, acometendo uma cadela SRD. As dermatopatias autoimunes foram diagnosticadas por histopatologia e representaram 0,93\% (2/215) dos casos, sendo o lúpus eritematoso a única patologia diagnosticada, acometendo um macho e uma fêmea, com sete anos e um ano de idade, respectivamente (Tab. 1). Os cães acometidos foram SRD e Pinscher.

Em 2,32\% (5/215) dos casos, as dermatopatias tinham outras causas. Além dos exames clínico e dermatológico, foi realizado exame histopatológico para estabelecer o diagnóstico. A cistomatose apócrina (Fig. 4a) representou $40 \%$ (2/5) dos casos, a dermatite seborreica, o cisto interdigital (Fig. 4b) e a acantose nigricans corresponderam a um caso cada $(20 \% ; 1 / 5)$ (Tab. 1). Os cães com cistomatose apócrina foram SRD $(50 \% ; 1 / 2)$ e Poodle $(50 \% ; 1 / 2)$; o cão com adenite seborreica era SRD; o cão com cisto interdigital, Pitbull; e a acantose nigricans foi SRD. 


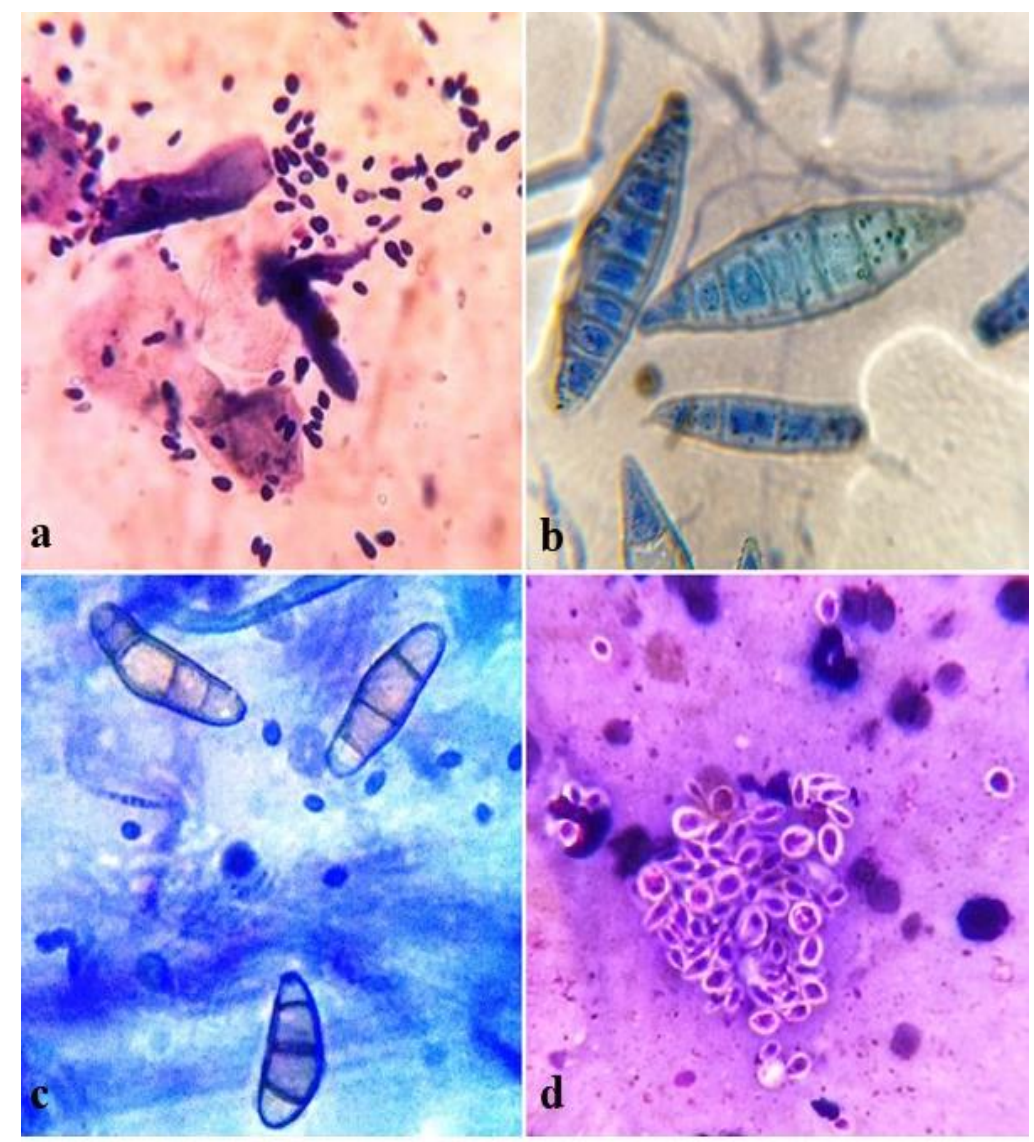

Figura 3. (a) Cão, macho, SRD, sete anos de idade. Exemplares de leveduras de Malassezia sp. no meio de células descamativas de amostra de secreção de ouvido. 100x, panótico rápido. (b) Cão, macho, SRD de quatro anos de idade. Exemplares de microconídios de M. canis. oriundo de cultura fúngica. 100x, giemsa. (c) Cão, fêmea, Shi Tzu, três anos de idade, cultura fúngica. Exemplares de microconídios de M. gypseum. 100x, giemsa. (d) Cão, fêmea, SRD, dois anos de idade. Exame citológico de amostra de secreção de lesão ulcerativa. Exemplares de fungos Sporothrix brasiliensis no interior do citoplasma de macrófagos e livres, em meio ao infiltrado inflamatório. 100x, panótico rápido.
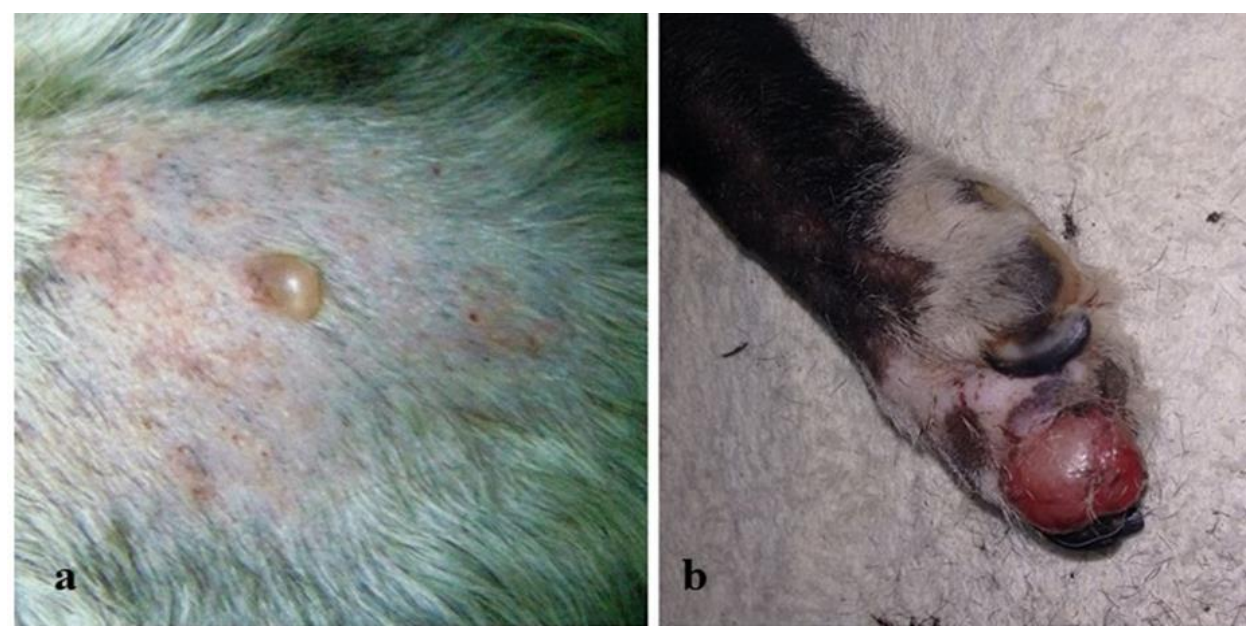

Figura 4. (a) Cão, fêmea, Poodle, 13 anos de idade. Cistomatose apócrina. (b) Cão, fêmea, Pitbull, seis anos de idade. Cisto interdigital. 


\section{DISCUSSÃO}

No presente estudo, a frequência das dermatopatias foi de 18,65\% (202/1.083), dados inferiores aos $31,38 \%$ observados por Cardoso et al. (2011). No entanto, esses autores analisaram um número de animais bem inferior ao deste estudo. Nesse levantamento, foi possível estabelecer os diagnósticos primários e secundários em 100,0\% das dermatopatias não tumorais em cães, resultados superiores a estudos descritos na literatura (Hill et al., 2006; Souza et al., 2009b). O diagnóstico foi realizado com base no histórico clínico, na anamnese, no exame físico geral e no especial dermatológico, associado à avaliação dos resultados obtidos nos exames complementares, como tricograma, parasitológico de pele, citológicos, microbiológicos (cultura bacteriana e fúngica), histopatológicos e técnicas moleculares, como a PCR e o sequenciamento genético para identificação de agentes.

O alto percentual de dermatopatias parasitárias observado no presente trabalho corrobora os dados publicados por Gasparetto et al. (2013), sendo a demodiciose a dermatopatia mais diagnosticada, o que supera os resultados observados em outros estudos (Sischo et al., 1989; Hill et al., 2006; Souza et al., 2009b e Cardoso et al., 2011). Esse fato possivelmente se deva, em parte, aos cães que tiveram sarna demodécica estarem sendo submetidos à reprodução por parte de alguns criadores (Willemse, 1995; Souza et al., 2009b; Freitas, 2011; Scott et al., 2013). No presente estudo, essa hipótese possivelmente seja justificada pelo fato de a demodiciose ter acometido, na maioria dos casos, cães com até um ano de idade, o que demonstra a importância da doença para a região estudada. Os machos foram mais acometidos que as fêmeas, e esse resultado contraria os dados de Gasparetto et al. (2013), em que a maioria dos animais acometidos eram fêmeas. A raça mais frequente foi a Pitbull, com $14,30 \%$, sendo inferior aos $40,50 \%$ encontrados em outro estudo, no Rio Grande no Norte (Rocha et al., 2008).

A escabiose representou $23,68 \%$ entre as dermatopatias parasitárias, diferenciando-se de estudos publicados (Rocha et al., 2008; Souza et al., 2009b; Cardoso et al., 2011; Gasparetto et al., 2013). Não foi verificada predisposição quanto ao sexo, o que difere dos achados de Cardoso et al. (2011), em que os machos foram mais acometidos, e de outro estudo (Gasparetto et al., 2013), em que é citado que a doença é mais frequente em fêmeas. Os cães com escabiose eram, na grande maioria, jovens com idade de até um ano; embora esse resultado corrobore os resultados obtidos por Freitas (2011), outros trabalhos apontam que não há predisposição por idade (Brum et al., 2007). No entanto, o elevado número no presente levantamento se deu devido a um surto que acometeu 14 cães do mesmo criador. Os cães SRD foram os mais acometidos. Freitas (2011) não relata predisposição racial, enquanto outros autores relataram que cães de raças definidas foram os mais acometidos (Rocha et al., 2008).

Não há muitos estudos com frequência de miíase. $\mathrm{O}$ presente trabalho mostrou maior percentual dessa doença em relação aos poucos trabalhos disponíveis na literatura (Scott et al., 2013; Souza et al., 2009b), em que os machos foram mais afetados que as fêmeas, diferindo dos achados de trabalhos que afirmaram haver predisposição sexual (Cansi e Demo, 2011; Cramer-Ribeiro et al., 2002). As idades mais frequentes foram de dois a cinco anos, e não foi observada, em termos percentuais, diferença entre cães SRD e de raças definidas. Porém, entre os cães de raça pura, o Cocker Spaniel e o Pitbull foram as raças mais acometidas. Esses resultados assemelham-se ao estudo de Cramer-Ribeiro et al. (2002).

A leishmaniose apresentou frequência de 3,95\%, o que diverge dos resultados de Gasparetto et al. (2013), que encontraram 12,4\%; entretanto, o presente trabalho foi realizado em uma região endêmica para a enfermidade, a qual possui as condições edafoclimáticas satisfatórias para $\mathrm{o}$ desenvolvimento do vetor (Missawa e Lima, 2006; Almeida et al., 2010). Por outro lado, a baixa frequência de leishmaniose neste trabalho pode ser explicada pelo fato de terem feito parte do levantamento apenas cães com lesões de pele.

Apesar de a literatura estimar que a tunguíase seja de elevada frequência e de distribuição mundial, sendo diagnosticada em várias espécies (Heukelbach et al., 2004 Loft Nissen, 2009), no presente trabalho a frequência da tunguíase foi baixa, acometendo apenas um cão, macho, da raça Pitbull, com três meses de idade. Entretanto, Souza et al. (2009b), no Rio Grande do Sul, observaram dois casos, sem indicação de sexo, raça e idade. No presente estudo, a baixa 
frequência de tunguíase pode estar relacionada ao avanço na conscientização e na prevenção da doença, além dos melhores cuidados dispensados aos animais de estimação por parte dos proprietários.

As dermatopatias bacterianas apresentaram frequência de 23,86\% dos diagnósticos. Esses resultados são semelhantes aos descritos por outros estudos (Scott et al., 2013; Souza et al., 2009b), no entanto são inferiores aos encontrados por Cardoso et al. (2011) e superiores às frequências observadas em outros estudos (Hill et al., 2006). Entretanto, Souza et al. (2009b) consideraram ectoparasitoses como doenças bacterianas. A piodermite foi a mais frequente doença bacteriana diagnosticada, com $63,45 \%$ dos casos, bem superior aos resultados de outros estudos, que variaram de 1,9\% (Cardoso et al., 2011) a 11,10\% (Hill et al., 2006). Os machos foram menos acometidos que as fêmeas; o grupo de idade mais frequente foi de dois a cinco anos, e os cães de raça definida foram mais acometidos em relação aos SRD. Entre os cães de raças puras, a Labrador e a Pitbull foram as mais frequentes. Esses resultados diferem, em alguns aspectos, do estudo de Cardoso et al. (2011). Quanto à existência de predisposição por sexo, idade e raça, isso não se pode confirmar (Souza et al., 2009b; Cardoso et al., 2011; Gasparetto et al., 2013).

A paniculite bacteriana idiopática, o abscesso cutâneo e a dermatite bacteriana apresentaram frequência de 9,62\% cada. A paniculite bacteriana idiopática e o abscesso subcutâneo acometeram mais os machos; porém, na dermatite bacteriana, as fêmeas foram mais frequentemente afetadas. A maioria dos cães com paniculite bacteriana idiopática tinha de dois a cinco anos de idade; já no abscesso cutâneo e na dermatite bacteriana, a idade dos animais afetados variou de até um ano a de 10 anos acima, respectivamente. Quanto ao padrão racial, os cães com paniculite bacteriana idiopática eram majoritariamente SRD. No abscesso subcutâneo e na dermatite bacteriana, os cães de raça definida representaram a maioria, sendo a Pitbull a mais frequente. Esses resultados indicam que, no presente estudo, não houve predileção por sexo, idade ou raça para as três doenças, corroborando os trabalhos publicados na literatura (Hill et al., 2006; Gasparetto et al., 2013).
A menor frequência observada dentre as dermatopatias bacterianas foi a foliculite/furunculose $(7,69 \%)$, resultado inferior aos achados de Cardoso et al. (2011) e superior os resultados obtidos por outros autores (Souza et al., 2009b; Gasparetto et al., 2013). Não foi observada predileção por sexo, idade ou raça, o que se deve possivelmente ao pequeno número de casos.

As infecções bacterianas na pele de cães são frequentemente descritas como causas secundárias de afecções cutâneas (Scott et al., 2013). No presente estudo, quase um quinto dos casos de dermatopatias bacterianas estavam associadas a doenças pruriginosas (dermatites alérgicas). Essa associação também foi descrita na literatura (Solomon et al., 2011; Vasconcelos et al., 2017). Nos restantes casos, não foi possível identificar a causa primária, devido ao não retorno do paciente à clínica para realização de exames adicionais e à falta de comunicação por parte dos tutores.

As dermatopatias alérgicas foram o terceiro grupo mais frequente, com 20\% (43/215) dos diagnósticos. Esses resultados foram semelhantes aos observados em estudo de Gasparetto et al. (2013) e diferentes de outros estudos (Souza et al., 2009b; Cardoso et al., 2011). Não foi observada diferença quanto ao sexo, semelhantemente ao descrito por Gross et al. (2005). A idade dos cães apresentou uma grande variação neste estudo, característica que também foi demonstrada em alguns estudos (Souza et al., 2009b; Nagelstein, 2010).

A dermatite atópica foi a dermatopatia alérgica mais frequente $(46,51 \%)$, corroborando os dados publicados por Souza et al. (2009b); outros estudos (Cardoso et al., 2011; Gasparetto et al., 2013) identificaram, respectivamente, que os casos de atopia correspondiam a $27,78 \%$ e $10,5 \%$ dos casos de dermatopatias de origem alérgicas. Semelhantemente a outro trabalho (Souza et al., 2009b), neste estudo não foi observada predileção sexual, diferindo de Vasconcelos et al. (2017), em cujo estudo as dermatites alérgicas foram mais frequentes nos machos do que nas fêmeas. No presente levantamento, a maioria dos animais acometidos tinha idade entre dois e cinco anos. Essa faixa etária também foi observada por Pélaud et al. (1998); porém, alguns animais tinham menos de um ano de idade, o que difere de dados descritos na literatura (Medleau e Hnilica, 2009). 
No presente estudo, a doença foi mais frequente em animais de raça pura, aspecto também descrito na literatura (Cardoso et al., 2011 e Vasconcelos et al., 2017), confirmando a predisposição por diferentes raças (Griffin e Deboer, 2001; White, 2003; Gross et al., 2005), mas acometendo também animais SRD (Lucas, 2007).

Em alguns estudos (Souza et al., 2009b; Cardoso et al., 2011; Gasparetto et al., 2013), a frequência da DAPE foi $16,50 \%, 4,80 \%$ e $4,29 \%$, respectivamente, resultados inferiores aos obtidos no presente estudo $(27,91 \%)$. Neste, houve acometimento mais frequente em machos que em fêmeas, diferentemente do trabalho de Gasparetto et al. (2013), que descrevem maior frequência em fêmeas. A maioria dos cães acometidos eram adultos, sem diferença entre cães SRD e de raça pura, assemelhando-se a outros trabalhos (Scott et al., 2013; Medleau e Hnilica, 2009). No presente estudo, o alto percentual se deve ao fato de que os casos de alergias a picadas de pulgas e carrapatos foram considerados DAPE.

A dermatite por hipersensibilidade alimentar foi observada em menor percentual por Souza et al. (2009b) e Cardoso et al. (2011), que encontraram $3,20 \%$ e 1,56\%; já em outro estudo, Salzo e Larsson (2009) observaram prevalência de $17,10 \%$, próxima ao presente estudo. Neste, os cães SRD, as fêmeas e os animais com idade superior a dois anos foram os mais acometidos. Esses dados diferem dos resultados publicados por Salzo e Larsson (2009), em que a raça Poodle foi a mais afetada e os machos foram os mais acometidos, corroborando quanto à idade.

A dermatite alérgica de contato é relatada como rara ou infrequente (Medleau e Hnilica, 2009). Entretanto, no presente estudo, correspondeu a 9,31\% dos diagnósticos de dermatopatias alérgicas, demonstrando que a doença ocorre com maior frequência, e afetou dois machos e duas fêmeas, variando a idade de 10 meses a 10 anos, sendo os cães SRD os mais acometidos. Esses resultados demonstram que a doença muitas vezes não é diagnosticada por aspectos como falta de conhecimento por parte dos clínicos de pequenos animais (Vasconcelos et al., 2017), reação imunológica tardia (Hargis e Ginn, 2013), semelhança com outras dermatites alérgicas (Gross et al., 2005), e também pelo fato de que ainda há uma certa resistência por parte dos clínicos e proprietários em realizar exames histopatológicos.

No presente estudo, apenas um animal foi diagnosticado com farmacodermia, sendo impossível avaliar qualquer aspecto em relação à predileção por idade, sexo ou raça. Em trabalho de Giger et al. (1985), é levantada a suspeita de haver predisposição genética a reações cutâneas (hipersensibilidade tipo III) com o uso de sulfadiazinas em cães da raça Pinscher. Em outro estudo, é levantada a hipótese de ligações covalentes entre as proteínas do indivíduo e os metabólitos das sulfonamidas, como a hidroxilamina, e a de que os compostos nitrosos podem induzir respostas imunes específicas adversas (Choquet et al., 2002). Há ainda outra hipótese: a da ativação dos linfócitos $\mathrm{T}$ durante a bioativação do fármaco, resultando na estimulação da resposta imune (Naisbitt, 2004; Trepanier, 2004).

As dermatomicoses representaram 16,97\% das dermatopatias diagnosticadas, diferenciando-se dos resultados de outros estudos (Cardoso et al., 2011; Gasparetto et al., 2013), em que se observaram 3,50\%, 4,00\%, respectivamente. A malasseziose, com uma acometimento de 75,67\%, foi a mais frequente, sendo superior aos resultados da literatura (Souza et al., 2009b; Cardoso et al., 2011; Gasparetto et al., 2013), porém inferior ao encontrado por Nascente et al. (2010). No presente estudo, os machos foram mais acometidos, o que difere dos achados descritos por Nascente et al. (2010). Semelhantemente a outros estudos (Nascente et al., 2010; Cardoso et al., 2011), a idade mais acometida foi de dois a cinco anos. Os cães de raças definidas foram mais afetados, sendo a Poodle a raça mais acometida. Em outro estudo que objetivou avaliar a frequência da malasseziose em cães, verificou-se maior frequência na raça Cocker Spaniel (Nascente et al., 2010).

A dermatofitose representou $21,63 \%$ do total de diagnósticos, entretanto, em outros estudos, houve variação da frequência: Machado et al. (2004), 6,00\%; Souza et al. (2009b), 1,20\%; Cardoso et al. (2011), 11,28\%; e Gasparetto et al. (2013), 10,50\%. Esse alto percentual de dermatofitose no presente levantamento pode estar ligado às influências climáticas, visto que João Pessoa-PB possui predominantemente clima quente e úmido, o que viabiliza a ocorrência da 
doença (Scott et al., 2013). As fêmeas foram mais afetadas, concordando com Cardoso et al. (2011). A maioria tinha de seis a nove anos de idade. Os cães de raça pura foram mais frequentes em relação aos SRD, e a raça mais acometida foi a Poodle. A esporotricose é pouco diagnosticada em cães, ocorrendo com bem mais frequente em gatos (Cruz, 2013), sendo considerada uma micose autolimitante no cão (Schubach et al., 2012). No presente estudo, a esporotricose foi diagnosticada em uma cadela SRD, com dois anos de idade. Essa dermatomicose foi anteriormente descrita em um cão da raça Boxer de seis anos de idade (Souza et al., 2009a).

As dermatopatias por causas diversas representaram 2,47\% dos diagnósticos; esse percentual foi semelhante ao encontrado em outros trabalhos (Souza et al., 2009b; Cardoso et al., 2011; Gasparetto et al., 2013). A cistomatose apócrina é uma condição rara, não neoplásica, que acomete os cães (Pulley e Stannard, 1990). No presente estudo, a cistomatose apócrina representou 40,00\% dos casos, acometendo duas fêmeas, com idades de nove e 14 anos, SRD e Poodle. Esses resultados corroboram os de Pulley e Stannard (1990), que descreveram a doença em animais de meia-idade ou mais velhos, não havendo predisposição conhecida de raça. A etiologia dessa condição é desconhecida, atribuindo-se a uma mudança degenerativa senil (Medleau e Hnilica, 2009). A adenite sebácea acometeu uma cadela de quatro meses de idade, o que é semelhante ao descrito por Farias et al. (2000). As raças comumente acometidas são Poodle Standard, Akita, Samoieda, Vizsla (Dunstan e Hargis, 1995; Medleau e Hnilica, 2009), Lhasa Apso, Cocker Spaniel, Chow Chow (Paterson, 2004) e Old English Sheepdog (Grognet, 2008), diferenciando do presente trabalho, que diagnosticou a doença em um animal SRD.

O cisto interdigital foi diagnosticado em uma cadela de seis anos de idade, da raça Pitbull. Em um estudo, as fêmeas foram mais acometidas; a maioria tinha três anos ou menos idade, sendo os animais de raça pura os mais afetados (Duclos et al., 2008). Ao avaliarem fatores epidemiológicos para o aparecimento de cistos interdigitais, Kovacs et al. (2005), observaram que a idade, o escore corporal e o tipo de piso onde os animais vivem constituem fatores importantes a se considerar. No presente trabalho, não foi possível avaliar ou comparar esses fatores por ter sido diagnosticado apenas um caso.

As dermatopatias autoimunes foram diagnosticadas em $0,92 \%$ dos casos. Essa frequência foi menor do que a frequência encontrada por Souza et al. (2009b) e semelhante ao observado em outros trabalhos (Cardoso et al., 2011; Gasparetto et al., 2013), em que se observaram $1,2 \%$ e $0,77 \%$ respectivamente. No presente levantamento, o lúpus eritematoso foi a única dermatopatia autoimune diagnosticada, acometendo um macho e uma fêmea, SRD e Pinscher, com idades de sete anos e um ano, respectivamente. Assim como no presente estudo, na literatura não foram observados indícios de predisposição quanto ao sexo e à idade; entretanto, é relatada maior incidência em cães com faixa etária média de seis anos (Scott et al., 2013).

\section{CONCLUSÕES}

Os resultados deste estudo permitem concluir que as categorias de dermatopatias não tumorais diagnosticadas em cães, no município de João Pessoa, Paraíba, em ordem decrescente, foram parasitárias, bacterianas, alérgicas, fúngicas, de causas diversas e autoimunes. Não foi possível afirmar a existência de predileção por sexo ou idade. No entanto, a faixa etária mais afetada foi o intervalo entre os dois e os cinco anos de idade. As raças puras foram mais frequentes em relação aos animais sem raça definida. Os exames físicos, incluindo anamnese detalhada, histórico clínico apurado, associado a exames dermatológicos e a exames complementares, foram ferramentas importantes para o diagnóstico das dermatopatias em cães. Estudos futuros, com amostragem maior e participação de maior número de clínicas veterinárias, são necessários para saber se existe predileção por raça, sexo e idade em cães afetados por dermatopatias.

\section{AGRADECIMENTOS}

À Capes, pela concessão da bolsa de doutoramento; ao Programa de Pós-Graduação em Medicina Veterinária - HV - UFCG; ao LPA - HV - UFCG e ao LPV - CCA - UFPB; aos técnicos em histotécnicas: Maria das Neves Gadelha Almeida, Temístoclis S. de Oliveira Neto e Ana Luzia Araújo Batista; e à Clínica Veterinária São Francisco. 


\section{REFERÊNCIAS}

ALMEIDA, A.B.P.F.; MENDONÇA, A.J.; SOUSA V.R.F. Prevalência e epidemiologia da leishmaniose visceral em cães e humanos, na cidade de Cuiabá, Mato Grosso, Brasil. Ciênc. Rural, v.40, p.1610$1615,2010$.

BRUM, L.C.; CONCEIÇÃO, L.G.; RIBEIRO, V.M. et al. Principais dermatoses zoonóticas de cães e gatos. Clín. Vet., v.12, 7p., 2007.

CANSI, E.R.; DEMO, C. Ocorrência de miíases em animais de companhia no Distrito Federal, Brasil. Acta Sci. Vet., v.39, p.982, 2011.

CARDOSO, M.J.L.; MACHADO, L.H.A.; MELUSSI, M. et al. Dermatopatias em cães: revisão de 257 casos. Arch. Vet. Sci., v.16, p.66-74, 2011.

CHOQUET, K.G.; VIAL, T.; DESCOTES, J. Allergic adverse reactions to sulfonamides. Curr. Allergy Asthma Rep., v.2, p.16-25, 2002.

CONCEIÇÃO, L.G.; LOURES, F.H.; CLEMENTE, J.T. et al. Biópsia e histopatologia de pele: um valioso recurso diagnóstico na dermatologia. I. Revisão. Clín. Vet., v.51, p.36-44, 2004.

CRAMER-RIBEIRO, B.C.; SANAVRIA， A.; OLIVEIRA, M.Q. et al. Inquérito sobre os casos de míase por Cochliomyia hominivorax em cães da zona sul do município do Rio de Janeiro no ano 2000. Braz. J. Vet. Res. Anim. Sci., v.39, p.171-175, 2002.

CRUZ, L.C.H. Complexo Sporothrix schenckii. Revisão de parte da literatura e considerações sobre o diagnóstico e a epidemiologia. Rev. Vet. Zootec., v.20, p.8-28, 2013.

DUCLOS, D.D.; HARGIS, A.M.; HANLEY, P.W. Pathogenesis of canine interdigital almar and plantar comedones and follicular cysts, and their response to laser surgery. Vet. Dermatol., v.19; p.134-141, 2008.

DUNSTAN, R.W.; HARGIS, A.M. The diagnosis of sebaceous adenitis in Standard Poodle dogs. In: BONAGURA, J.D. (Ed.). Kirk's current veterinary therapy XII. Philadelphia: W.B. Saunders, 1995. p.619-622.

FARIAS, M.R.; PERES, J.A.; FABRIS, V.E. et al. Adenite sebácea granulomatosa em cães da raça akita. Rev. Clinic. Vet., v.25, p.33-38, 2000.

FREITAS, A.K.S. Estudo retrospectivo de dermatites por ácaros causadores de sarna, em cães atendidos no Hospital Veterinário de Patos. 2011. 34f. Monografia (Conclusão do Curso de Medicina Veterinária) - Universidade Federal de Campina Grande, Patos, PB.
GASPARETTO, N.D.; TREVISAN, Y.P.A.; ALMEIDA N.B. et al. Prevalência das doenças de pele não neoplásicas em cães no município de Cuiabá, Mato Grosso. Pesqui. Vet. Bras., v.33, p.359-362, 2013.

GIGER, U.; WERNER, L.L.; MILICHAMP, N.J. et al. Sulfadiazine-induced allergy in six Doberman Pinschers. J. Am. Vet. Med. Assoc., v.186, p.479484, 1985.

GRIFFIN. C.E.; DEBOER, D.J. The ACVD task force on canine atopic dermatitis (XIV): clinical manifestations of canine atopic dermatitis. Vet. Immunol. Immunopathol., v.8, p.255-269, 2001.

GROGNET, J. Sebaceous adenitis. Akc Gazette, v. 125, p.28-29, 2008.

GROSS, T.L.; IHRKE, P.J.; WALDER, E.J. Skin diseases of the dog and cat. Clinical and histopathologic diagnosis. 2.ed. Oxford: Blackwell, 2005. 932p.

HARGIS, A.M.; GINN P.E. O Tegumento. In: ZACHARY, J.F.; MCGAVIN, M.D. (Eds). Bases da patologia em veterinária. 5.ed. Rio de Janeiro: Elsevier, 2013. p.975-1186.

HEUKELBACH, J.; COSTA, A.M.L.; WILCKE, T. et al. The animal reservoir of Tunga penetrans in severely affected communities of north-east Brazil. Med. Vet. Entomol., v.18, p.329-335, 2004.

HILL, P.B.; LO, A. EDEN, C.A. et al. Survey of the prevalence, diagnosis and treatment of dermatological conditions in small animals in general practice. Vet. Rec., v.158, p.533-539, 2006.

KOVACS, M.S.; MCKIERNAN, S.; POTTER, D.M. An epidemiological study of interdigital cysts in a research Beagle colony. Contemp. Top. Lab. Anim. Sci., v.44, p.17-21, 2005.

LOFT, K.E.; NISSEN, M.H. Tunga penetransin a young dog imported to Denmark from Brazil; a case report. Vet. Dermatol., v.20, p.300-303, 2009.

LUCAS, R. Diagnóstico diferencial das principais dermatopatias alérgicas em cães. Nosso Clínico, v.10, p.6-18, 2007.

MACHADO, M.L.S.; APPELT, C.E.; FERREIRO, L. Dermatófitos e leveduras isolados da pele de cães com dermatopatias diversas. Acta. Sci. Vet., v.32, p.225-232, 2004.

MEDLEAU, L.; HNILICA, K.A. Dermatologia de pequenos animais: atlas colorido e guia terapêutico. 2.ed. São Paulo: Roca, 2009. 512p. 
MISSAWA, N.A.; LIMA, G.B.M. Distribuição espacial de Lutzomyia longipalpis (Lutz et Neiva, 1912) e Lutzomyia cruzi (Mangabeira, 1938) no Estado de Mato Grosso. Rev. Soc. Bras. Med. Trop., v.39, p.337-340, 2006.

NAGELSTEIN, A.F. Patogenia da dermatite atópica em cães. 2010. 38f. Monografia

(Especialização em Dermatologia de animais de companhia) - Unigran, Dourados, MS.

NAISBITT, D.J. Drug hypersensitivity reactions in skin: understanding mechanisms and the development of diagnostic and predictive tests. BTS Annual Congress 194:179-196, 2004.

NASCENTE, P.S.; SANTIN, R.; MEINERZ, A.R.M. et al. Estudo da frequência de malassezia pachydermatis em cães com otite externa no rio grande do sul. Cienc. Anim. Bras., v.11, p.527-536, 2010 .

PATERSON, S. Successful therapy of sebaceous adenitis with topical cyclosporine in 20 dogs. Vet. Dermatol., v.15, p.64-64, 2004.

PÉLAUD, P.; GUAGUÉRE ALHAIDARI, N.; FAIVRE, D. et al. Reevaluation os diagnostic criteria of canine atopic dermatitis. Rev. Med. Vet., v.149, p.1057-1064, 1998.

PENA, S.B. Frequência de dermatopatias infecciosas, parasitárias e neoplásicas em cães na região de Garça, São Paulo - Brasil. 2007. 52f. Dissertação (Mestrado em Medicina Veterinária Clínica Veterinária) - Faculdade de Medicina Veterinária e Zootecnia, Universidade Estadual Paulista, Botucatu, SP.

PEREIRA, S.A.; MENEZES, R.C.; GREMIÃO, I.D. et al. Sensitivity of cytopathological examination in the diagnosis of feline sporotrichosis. J. Feline Med. Surg., v.13, p.220, 2011.

PULLEY, L.T.; STANNARD, A.A. Tumors of the skin and soft tissues. In: MOULTON, J.E. (Ed.) Tumors in domestic animals. 3.ed. California: Press, Berkeley, 1990. p.66.

ROCHA, G.S.; AHID, S.M.M.; SUASSUNA, A.C.D.B. et al. Frequência de ácaros em cães e gatos no município de Mossoró, Rio Grande do Norte. Acta Sci. Vet., v.36, p.263-266, 2008.
SALZO, P.S.; LARSSON, C.E. Hipersensibilidade alimentar em cães. Arq. Bras. Med. Vet. Zootec., v.61, p.598-605, 2009.

SCHUBACH, T.M.P.; MENEZES, R.C.; WANKE, B. Sporotrichosis. In: GREENE, C.E. (Ed.). Infectious diseases of the dog and cat. 4.ed. St Louis: Elsevier, 2012. p.645-650

SCOTT, D.W.; MILLER, D.H.; GRIFFIN, C.E. In: Muller and kirk's small animal dermatology. 7.ed. W.B. Philadelphia: Saunders, 2013. 948p.

SISCHO, W.M.; IHRKE, P.J.; FRANTI, C.E. Regional distribution of ten skin diseases in dogs. $J$. Am. Vet. Med. Assoc., v.195, p.752-756, 1989.

SOLOMOM, S.B.; FARIAS, M.R.; PIMPÃO, C.T. et al. Piodermite bacteriana em cães com dermatite atópica - revisão de literatura. MedVet Dermatol., v.1, p.244-255, 2011.

SOUZA, N.T.; NASCIMENTO, A.C.B.M.; SOUZA, J.O.T. et al. Esporotricose canina: relato de caso. Arq. Bras. Med. Vet. Zootec., v.61, p.572-576. 2009a.

SOUZA, T.M.; FIGHERA, R.A.; SCHMIDT, C. et $a l$. Prevalência das dermatopatias não-tumorais em cães do município de Santa Maria, Rio Grande do Sul (2005-2008). Pesqui. Vet. Bras., v.29, p.157162. $2009 \mathrm{~b}$.

TREPANIER L.A. Idiosyncratic toxicity associated with potentiated sulfonamides in the dog. J. Vet. Pharmacol. Therap. 27:129-138, 2004.

VASCONCELOS, J.S.; OLIVEIRA NETO, T.S.; NASCIMENTO, H.H.L. et al. Caracterização clínica e histopatológica das dermatites alérgicas em cães. Pesqui. Vet. Bras., v.37. p.248-256, 2017.

WHITE, P.D. Atopia. In: BICHARD, S.J.; SHERDING, R.G. (Eds.). Manual sauders clinica pequenos animais. 2.ed. São Paulo: Roca, 2003. p.372-380.

WILlEMSE, T. Dermatologia clínica de cães e gatos. 2.ed. São Paulo: Manole, 1995. 141p. 